\title{
La Urbanización y la Vivienda Vernácula en la Villa de San Antonino Castillo Velasco, Oaxaca, México
}

\author{
The Urbanization and Vernacular Housing in the Villa de San Antonino \\ Castillo Velasco, Oaxaca, Mexico
}

\section{A Urbanização e Habitação Vernacular na Villa de San Antonino Castillo Velasco, Oaxaca, México}

José Israel Mayorga Hernández

Arquitecto, Maestría en Diseño Digital.

Universidad Autónoma "Benito Juárez" de Oaxaca, México.

jisraelmayorga@gmail.com

(iD) https://orcid.org/0000-0001-9835-1340

Alejandra Pimentel Calvo

Arquitecta, Maestría en Educación.

Universidad Autónoma "Benito Juárez" de Oaxaca, México.

alexpimentelcalvo@yahoo.es

(iD) https://orcid.org/0000-0003-1203-0277

Aurea Natividad Figueroa Gil

Arquitecta, Maestría en Valuación.

Universidad Autónoma "Benito Juárez" de Oaxaca, México.

aufi1907@hotmail.com

Recibido: noviembre 20 de 2020

Aceptado: marzo 18 de 2021

https://orcid.org/0000-0002-1412-2645

Publicado: abril 5 de 2021

\section{RESUMEN}

Aspectos como el crecimiento urbano exponencial y la falta de políticas públicas congruentes para la conservación de las viviendas vernáculas, inciden de forma directa en la extinción de la vivienda vernácula en comunidades como es el caso de la Villa de San Antonino Castillo Velasco, Oaxaca, México. El objetivo de la investigación es identificar y registrar las viviendas vernáculas existentes en el sitio de estudio, para su conservación. La metodología utilizada es mixta. Como hallazgo principal se encontró un total de 1.394 viviendas de uso particular; de las cuales 156 conservan tipología vernácula de adobe. Por lo tanto, el reconocimiento y protección de los gobiernos a la vivienda vernácula, es coyuntural para legarlo a las generaciones futuras, como identidad y patrimonio integral del paisaje cultural.

Palabras clave: Arquitectura; Patrimonio Vernáculo; Adobe; Vivienda; Urbanización 


\section{ABSTRACT}

Aspects such as exponential urban growth and the lack of congruent public policies for the conservation of vernacular dwellings, have a direct impact on the extinction of vernacular housing in communities such as the Villa de San Antonino Castillo Velasco, Oaxaca, Mexico. The objective of the research is to identify and register the vernacular dwellings in the study site, for their conservation. The methodology used is mixed. The main finding was a total of 1,394 homes for private use, of which 156 conserve vernacular adobe typology. Therefore, the recognition and protection of the governments to the vernacular housing, is conjunctural to bequeath it to the future generations, as identity and integral patrimony of the cultural landscape.

Keywords: Architecture; Vernacular Heritage; Adobe; Living Place; Urbanization.

\section{RESUMO}

Aspectos como o crescimento urbano exponencial e a falta de políticas públicas congruentes para a conservação das moradias vernáculas têm um impacto direto na extinção das moradias vernáculas em comunidades como a Villa de San Antonino Castillo Velasco, Oaxaca, México. O objetivo da pesquisa é identificar e cadastrar as habitações vernáculas do local de estudo, para sua conservação. A metodologia usada é mista. A principal descoberta foi um total de 1.394 residências de uso privado; dos quais 156 conservam a tipologia vernacular de adobe. Portanto, o reconhecimento e proteção dos governos à habitação vernácula, é conjuntural para legá-la às gerações futuras, como identidade e patrimônio integral da paisagem cultural.

Palavras-chave: Arquitetura; Herança vernácula; Adobe; Local de Moradia; Urbanização.

\section{INTRODUCCIÓN}

El crecimiento acelerado de las ciudades en México, la hegemonización en el poder, la constante migración del campo a las ciudades, la influencia en políticas públicas para la construcción de la vivienda, a partir del siglo $\mathrm{XX}$, con materiales industrializados incide en la extinción de la vivienda vernácula en comunidades como es el caso de la Villa de San Antonino Castillo Velasco, Oaxaca, México.

En la época del virreinato en 1649 , se fundó el pueblo de San Antonino, Ocotlán, Oaxaca. Con fecha 12 de diciembre del año de 1889, mediante Decreto No. 36 del gobierno del estado de Oaxaca, erige en "Villa" el pueblo de San Antonino Ocotlán, del distrito del mismo nombre, llevando en lo sucesivo el nombre de: "Villa de San Antonino Castillo Velasco".

La Villa de San Antonino Castillo Velasco, tiene una población de 5,354 habitantes (INEGI, 2010); su localidad es de tipo urbana, con extensión territorial de $26.79 \mathrm{Km}^{2}$, su densidad de población es de 503.97 habitantes $/ \mathrm{km}^{2}$ (INEGI, 2010).

Uno de los hitos importantes en la Villa de San Antonino Castillo Velasco es el templo del Siglo XVII, dedicado a San Antonino Obispo, y, por ende, la religión católica es la dominante en la comunidad. La traza urbana es de tipo reticular.

El objetivo de la presente investigación es identificar y registrar para su conservación, la vivienda vernácula de la Villa de San Antonino Castillo Velasco, México. Se caracterizó la vivienda vernácula con adobe, por elementos constructivos: muros con bloques de adobe, cimentación a base de piedra cantera o piedra de río, vigas de madera, en losas de azotea o techo con tabique rojo (media tabla), tejas, en los pisos, loseta de barro cocido; en lo que respecta a las puertas y ventanas son con base de madera de pino con sus respectivos dinteles.

La comunidad cuenta con 1.394 viviendas de uso particular (INEGI, 2010). Los resultados de la elaboración propia de la investigación emanaron que hay 156 viviendas vernáculas construidas con adobe que conservan su tipología y materiales de la región.

Para poder lograr la conservación de la vivienda vernácula con adobe en la Villa de San Antonino Castillo Velasco, es necesario considerar el modo de construir emanado de la propia comunidad, coherencia en el tipo arquitectónico vernáculo, la aplicación de sistemas, oficios y técnicas tradicionales de construcción. 
Los diferentes órdenes de gobierno deben reconocer en la comunidad el mantener su modo de vida tradicional y protegerlos a través de todos los medios posibles, tanto legales como administrativos y financieros, y legarlo a las generaciones futuras, como identidad y patrimonio integral del paisaje cultural.

\section{MARCO TEÓRICO}

Patrimonio Vernáculo y Patrimonio Cultural Inmaterial. De acuerdo con la carta del Patrimonio Vernáculo construido por el International Council on Monuments and Sites, por sus siglas en inglés (ICOMOS), en español el Consejo Internacional de Sitios y Monumentos, de 1999, en México, establece que el Patrimonio Tradicional o Vernáculo construido es la expresión fundamental de la identidad de una comunidad, de sus relaciones con el territorio y, al mismo tiempo, la expresión de la diversidad cultural frente al mundo. El Patrimonio Vernáculo construido constituye el modo natural y tradicional en que las comunidades han producido su propio hábitat.

También podemos relacionar el Patrimonio Tradicional Vernáculo con el Patrimonio Intangible; en la convención internacional para la salvaguarda del Patrimonio Cultural Inmaterial de la United Nations Educational Scientific and Cultural Organization por sus siglas en inglés (UNESCO), en español la Organización de las Naciones Unidas para la Educación, la Ciencia y la Cultura, de 2003, define:

Patrimonio Cultural Inmaterial, son los usos las representaciones, expresiones, conocimientos y técnicas -junto con los instrumentos, objetos, artefactos, y espacios culturales que le son inherentes- que las comunidades, los grupos, y en algunos casos los individuos reconozcan como parte integrante de su patrimonio cultural. Este patrimonio cultural inmaterial, que se trasmite de generación en generación, es recreado constantemente por las comunidades y grupos en función de su entorno, su interacción con la naturaleza, y su historia, infundiéndoles un sentido de identidad y continuidad y contribuyendo así a promover el respeto de la diversidad cultural y la creatividad humana. (UNESCO, 2003).
En la definición de Patrimonio Cultural e Inmaterial hay relación con la arquitectura vernácula.

\section{Conceptos Principales del Proceso de Urbanización y el Sistema Urbano Nacional} en México. Para definir el ámbito urbano $y_{\text {, en }}$ específico, el Sistema Urbano Nacional en México, es preciso hacer referencia a las nociones de ciudad, crecimiento urbano, desarrollo urbano y proceso de urbanización. Dichos conceptos toman como parámetro exclusivo el tamaño de la población; sin embargo, la mayor limitación de este criterio es que deja fuera los componentes funcional, físico, cultural e inmaterial, inherentes a la base económico-territorial y que son los determinantes en el proceso de urbanización. Es decir, que el proceso de urbanización tiene origen en la modalidad de proceso de producción, de ahí su vínculo con el desarrollo económico, por lo que expresa una razón de posibilidad en la cual los cambios en las modalidades de producción se reflejarán en la dinámica de crecimiento de las ciudades (Figura 1).

\section{La Arquitectura Vernácula y los Elementos} Intangibles. La vivienda vernácula no es una edificación netamente del medio físico, existen otros factores como lo son: religiosos, sociales, económicos y culturales. Los usos y costumbres se hacen presentes.

Francisco Javier López Morales realiza un estudio formal de lo intangible en la Arquitectura, y es quien desarrolla la idea de estructuras significativas a partir de los rituales y recorridos significativos en el espacio vernáculo. El espacio vernáculo de la casa maya se constituye en una estructura de valores simbólicos, que dan a partir de rituales de los días de muertos (López, 1993: págs. 23-34). López Morales establece tres influencias que inciden en la configuración de dicha arquitectura: prehispánica, española y árabe (López, 1989).

(León, 1997) sostiene que las construcciones vernáculas en el periodo prehispánico estaban basadas en la cosmovisión náhuatl.

(González, 1996) propone una lectura semántica de la vivienda, a partir de los códices prehispánicos. Por lo tanto, la arquitectura vernácula está vinculada con lo intangible, como identidad y patrimonio integral del paisaje cultural. 


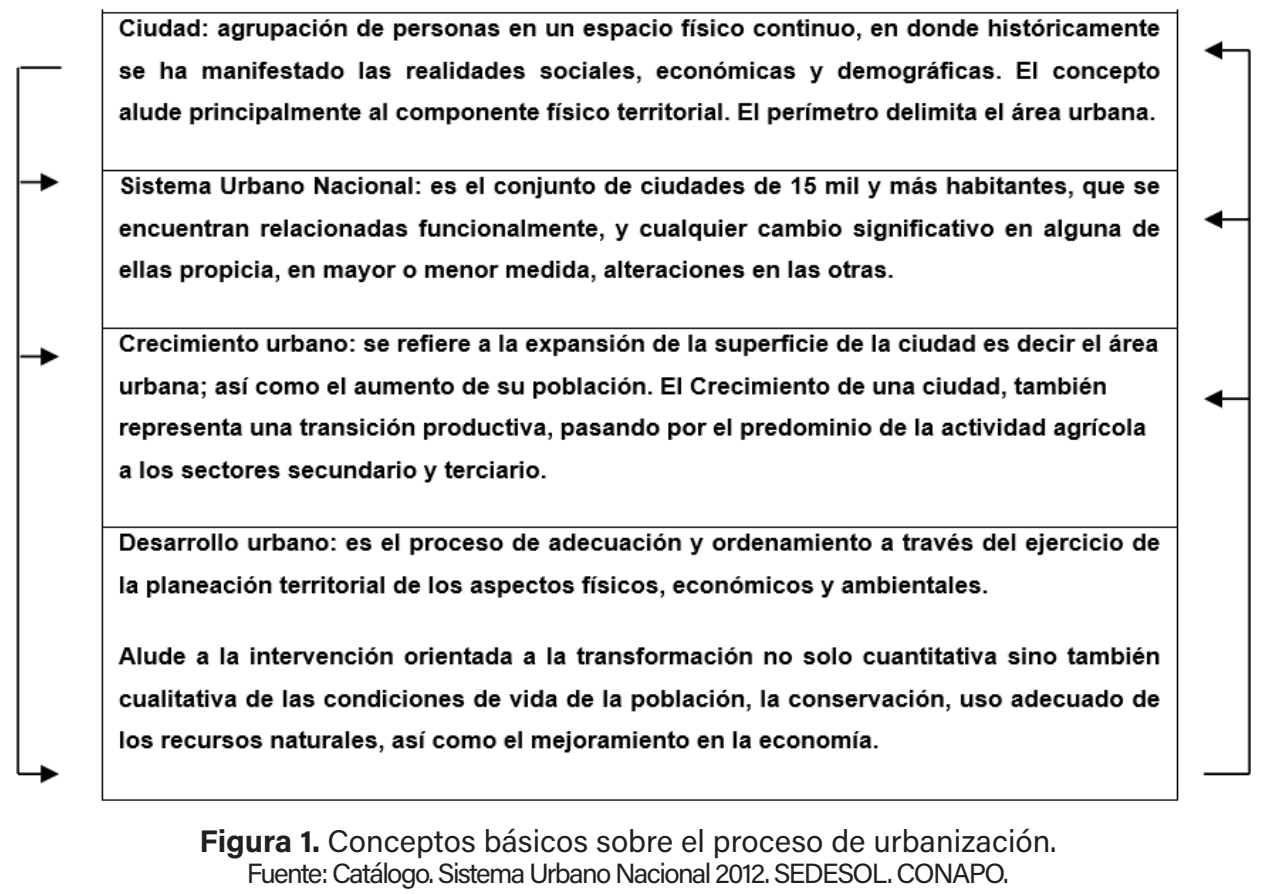

\section{Necesario el Reconocimiento en las Políticas Públicas de la Vivienda Vernácula por los diferentes Órdenes de Gobierno}

Ámbito Federal. En el ámbito del gobierno federal de México, se establece el Plan Nacional de Desarrollo (PND 2019-2024), con la política social: territorio y desarrollo sostenible; mediante su programa Desarrollo Urbano y Vivienda, que solo considera a 14 municipios del país en ciudades fronterizas, para aminorar el contraste entre las zonas con hoteles y de gran lujo con colonias marginadas. Se realizan obras de rehabilitación y/o mejoramiento de espacios públicos. Se favorece a la vivienda social con el mejoramiento, ampliación y sustitución de vivienda.

La política federal del gobierno mexicano no considera la vivienda vernácula, en ningún aspecto, y con ello queda vulnerable su conservación.

Ámbito Estatal. En lo que respecta al Plan Estatal de Desarrollo del Estado de Oaxaca (PED 20162022), en su Eje 5, Oaxaca Sustentable, manifiesta, detonar las riquezas naturales y culturales de manera consciente e inteligente para conservar los recursos y garantizar su conservación. En cuanto a política pública expresa:
En materia de ordenamiento del territorio, es fundamental definir políticas públicas que permiten planear, orientar y administrar en el marco de la legalidad del desarrollo físico y la utilización del suelo en la entidad particularmente en el ámbito natural, social y urbano, económico y de infraestructura (PED 2016-2022 Pág. 21).

Ámbito Municipal. En el ámbito municipal, el Plan de Desarrollo Municipal 2019-2021 del municipio de San Antonino Castillo Velasco, Oaxaca, no contempla la tipología de vivienda vernácula. Obtiene datos generados de vivienda de acuerdo con los parámetros sociales que implementa el Instituto Nacional de Estadística y Geografía por sus siglas (INEGI).

Inclusión en la Política Pública. Es evidente que en las políticas públicas de los diferentes órdenes de gobierno no incluyen la vivienda vernácula para su conservación, como patrimonio cultural e intangible. A pesar de que existe una postura internacional por el ICOMOS sobre la vivienda vernácula, las políticas públicas del Estado Mexicano no se alinean a las disposiciones internacionales. 


\section{METODOLOGÍA}

Derivado de la observación respecto a la extinción de la vivienda vernácula con adobe, se desarrolla el proyecto de investigación que refiere la urbanización y la vivienda vernácula del municipio de la Villa de San Antonino Castillo Velasco, región del valle de Oaxaca, México. La metodología es mixta. Se determina un tipo de vivienda con carácter arquitectónico vernáculo, de acuerdo con los materiales de construcción empleados de la región, situación geográfica, clima, usos y costumbres, por lo que, en la elaboración propia para el trabajo de investigación de campo, se generó una ficha como instrumento para su respectiva identificación y registro.

Investigación Documental y de Campo. Se identifica la tipología de la vivienda con carácter vernáculo de acuerdo con los materiales de construcción empleados en la comunidad de la villa de San Antonino Castillo Velasco, perteneciente a la región de Valles Centrales de Oaxaca, México.

Se toma en cuenta la disposición arquitectónica de la vivienda: cimentación, muros con bloques de adobe, techos con bóveda catalana, petatillo, teja (española), elementos de soporte de madera en vigas, dinteles; puertas de madera, acabados en muros con estuco, pisos con piedra cantera, pisos de tierra.

Se obtiene información documental geoestadística urbana, generada por el Instituto Nacional de Estadística y Geografía por sus siglas (INEGI), y se elaboran planos por cuadrantes respecto a la traza urbana reticular, tomando como eje central el templo católico y el palacio municipal; se procede al levantamiento fotográfico y ubicación de las viviendas vernáculas.

Se realiza la división por Cuadrante de la traza urbana, respecto al norte magnético. La división por Cuadrante se identifica de la siguiente manera: Cuadrante 1 Noroeste; Cuadrante 2 Noreste; Cuadrante 3 Suroeste; y Cuadrante 4 Sureste.

Se diseñó un cuestionario para aplicar a las autoridades municipales acerca de la estructura organizativa del municipio con el objetivo principal de recabar información primaria, secundaria y terciaria de la Villa de San Antonino Castillo
Velasco, Oaxaca, México; en relación económica, social, cultural, medio ambiente y tipos de vivienda en la población con el exterior, diversificación de actividades económicas, turísticas movilidad de mano de obra y capital humano y vinculación económica con el gobierno.

Una vez recaba la información se analizó y se ilustró con gráficas los indicadores como resultado de la investigación para dar paso a las conclusiones, observaciones y sugerencias.

\section{DESARROLLO}

\section{Ubicación Geográfica del Área de Estudio}

La Villa de San Antonino Castillo Velasco, Oaxaca, México. Oaxaca es una entidad federativa de la república mexicana, que cuenta con una extensión territorial de $91,783 \mathrm{~km}^{2}$ (Figura 2) representa el $4.78 \%$ de la superficie nacional ocupando el quinto lugar como el estado más grande de la nación. Su división política es de 8 regiones: Cañada, Costa, Istmo, Mixteca, Papaloapan, Sierra Sur, Sierra Norte y Valles Centrales (Figura 3). Dividido en 30 distritos, 570 municipios de los cuales 418, están basados en usos y costumbres (INEGI, 2015).

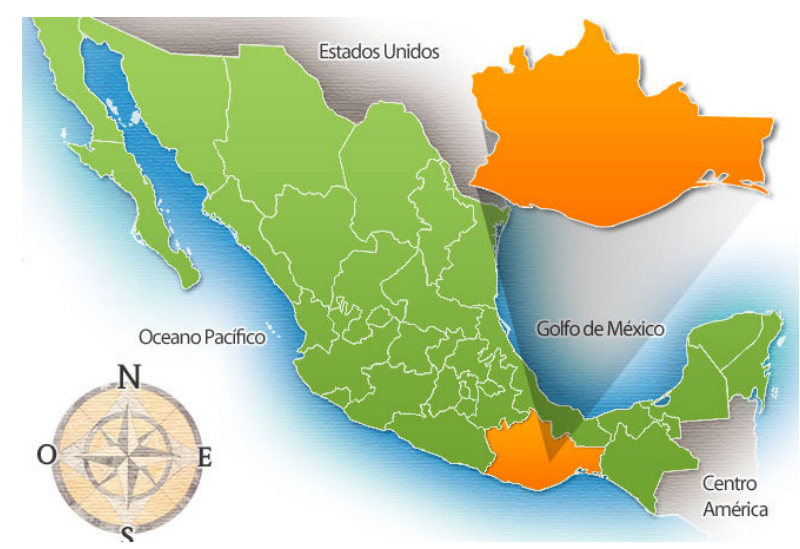

Figura 2. Marco Geoestadístico.

Fuente: INEGI. 2010.

El municipio de San Antonino Castillo Velasco tiene una extensión territorial de $26.79 \mathrm{Km}^{2}$ (Figura 4). De la capital de Oaxaca, al municipio de San Antonino Castillo Velasco, hay una distancia de $29.5 \mathrm{Km}$ (Figura 5). 


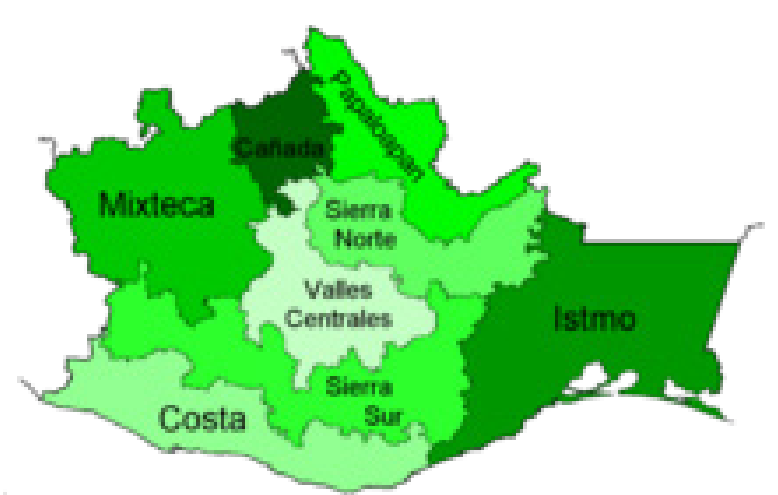

Figura 3. División política regional del estado de Oaxaca. Fuente: INEGI. 2010.

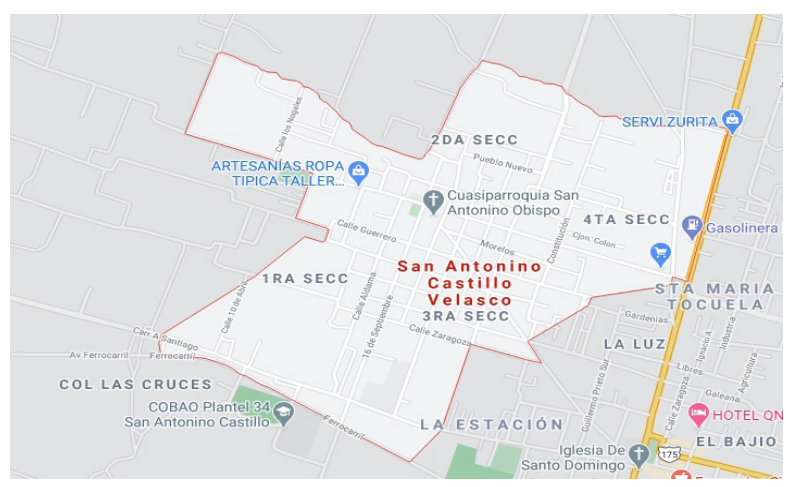

Figura 4. Delimitación territorial, Municipio de San Antonino Castillo Velasco, Oaxaca, México. Fuente: INEGI. 2010.

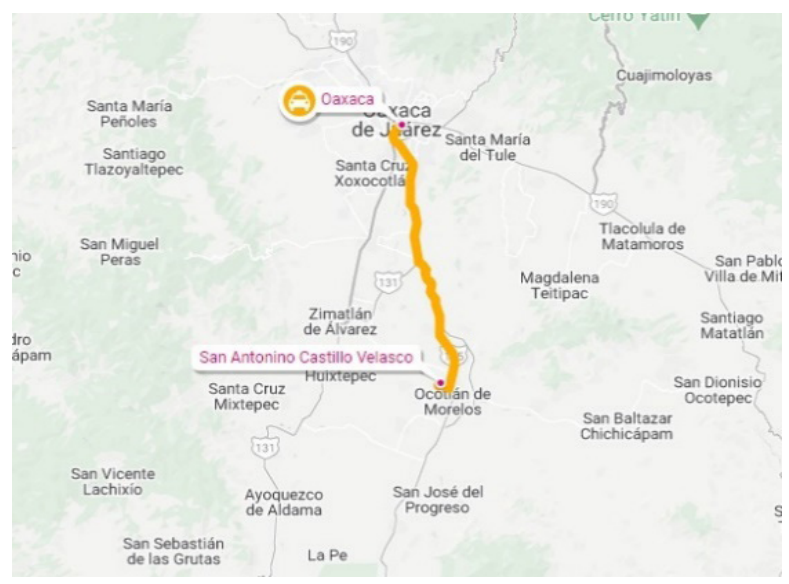

Figura 5. Distancia 29.5Km, del municipio de la capital de Oaxaca, al municipio de la Villa de San Antonino Castillo Velasco, Oaxaca, México.

Fuente: INEGI. 2010.

Fundación de San Antonino Castillo Velasco, Oaxaca, México. Conforme a documentación al resguardo en el Palacio Municipal de la Villa de San Antonino Castillo Velasco, el pueblo se fundó en el año de 1649, por Nicolás Hernández, Martín Ángel Toledo y Manuel Salmerón, en tierras que habían sido cedidas a sus familias a principios de la época colonial. El plano topográfico de los terrenos de San Antonino Ocotlán, del año 1862, hoy con la denominación de la Villa de San Antonino Castillo Velasco; los puntos que aparecen en la línea de mohoneras ó mojoneras, son piedras enterradas con las que lleva el lindero sirviendo de mohoneras: el color verde claro representa la hera del terreno de San Antonino (Figura 6).

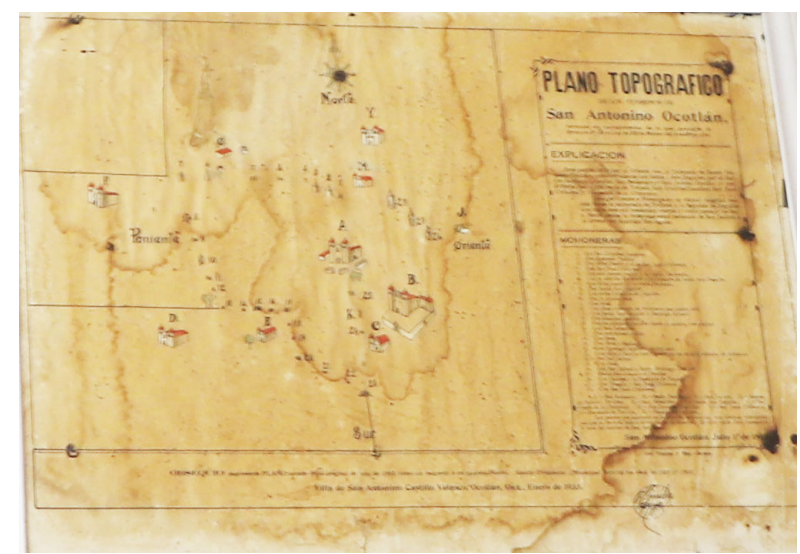

Figura 6. Plano topográfico sacado de su original del año de 1862. Villa de San Antonino Castillo Velasco Ocotlán, Oaxaca, México.

Fuente: Archivo municipal. Año 2020.

El 12 de diciembre de 1889, el gobernador del Estado de Oaxaca, Albino Zertuche, mediante Decreto Número 36, se erige en Villa al pueblo de San Antonino Ocotlán del distrito del mismo nombre, llevando en lo sucesivo en nombre de "Villa de San Antonino Castillo Velasco", recibe el apellido del ilustre político liberal Don José María Castillo Velasco (Figura 7).

Se fundó en el siglo XVII, época en la cual se utilizaban los recursos y las materias primas de la región, como la arcilla, adobe, madera, ladrillos de media tabla, ladrillos de arcilla y tejas, para la construcción de viviendas. Dando origen a la arquitectura vernácula. 




Figura 7. Decreto Numero 36. Villa de San Antonino Castillo Velasco.

Fuente: Archivo municipal. Año 2020.

La Traza Urbana de la Villa de San Antonino Castillo Velasco, Oaxaca, México. Los municipios que limitan con la Villa de San Antonino Castillo Velasco, Oaxaca, México, son: San Martín Tilcajete, San Antonino el Alto, Santiago Apóstol, y Ocotlán de Morelos.

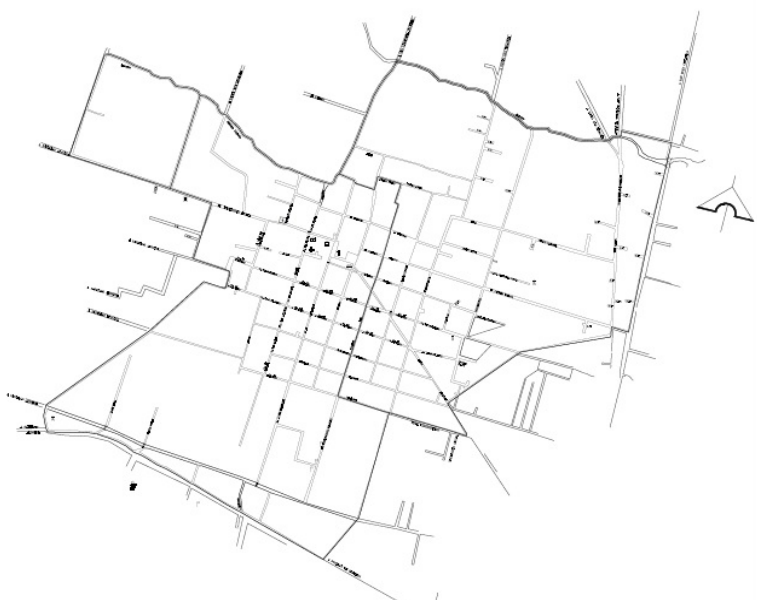

Figura 8. Traza urbana de la Villa de San Antonino Castillo Velasco.

Elaboración propia. Autores. Año 2020.
Hitos. La traza urbana de la Villa de San Antonino Castillo Velasco, es de forma reticular (Figura 8), en el centro se localiza el hito del templo católico correspondiente al siglo XVII, dedicado a San Antonino Obispo (Figura 9), al frente de la fachada principal del templo está el palacio de gobierno municipal (Figura 10).

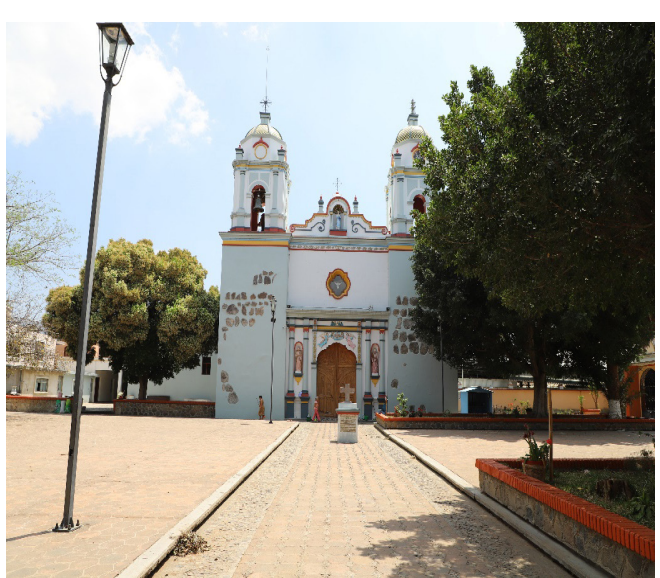

Figura 9. Templo del Siglo XVII de San Antonino Castillo Velasco.

Fuente: Autores. Año 2020.

Fue en el año de 2006 cuando se demolió el antiguo Palacio Municipal de carácter vernáculo de San Antonino Castillo Velasco y se construyó uno nuevo sin tomar en cuenta los antecedentes históricos del anterior Palacio Municipal.

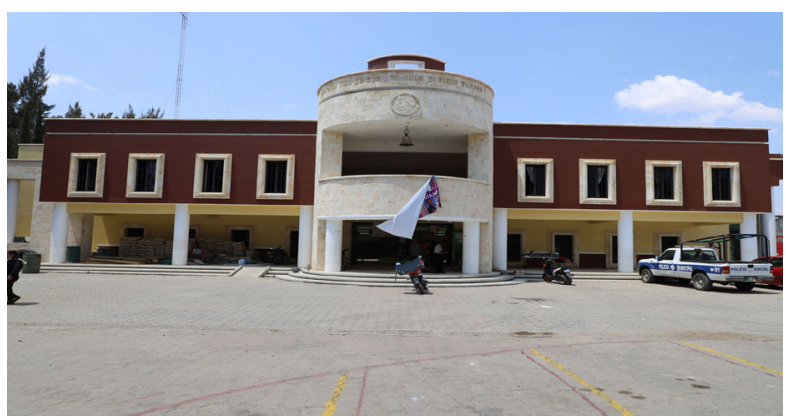

Figura 10. Palacio Municipal de San Antonino Castillo Velasco

Fuente: Autores. Año 2020.

La Vivienda Vernácula de la Villa de San Antonino Castillo Velasco, Oaxaca, México. Desde su fundación la Villa de San Antonino Castillo Velasco, las viviendas fueron de carácter vernáculo, edificadas con materiales de la región para los cimientos se utilizaron materiales de 
piedra de río, piedra braza, piedra cantera; los muros de la vivienda y bardas perimetrales fueron construidas con bloques de adobe; los techos de bóveda catalana, petatillo y teja española; los elementos de soporte construidos con madera de pino: vigas de madera, tirantes de madera, largueros, contrafuertes, pilares, dinteles en puertas y ventanas; los acabados en muros aplanados con estuco, los pisos de piedra cantera, tabique rojo y tierra.

Al transcurrir las diferentes etapas desde el virreinato, México independiente, guerra de revolución, guerra cristera y época actual. Pocas son las viviendas con características vernáculas que aún quedan de pie (Figura 11).

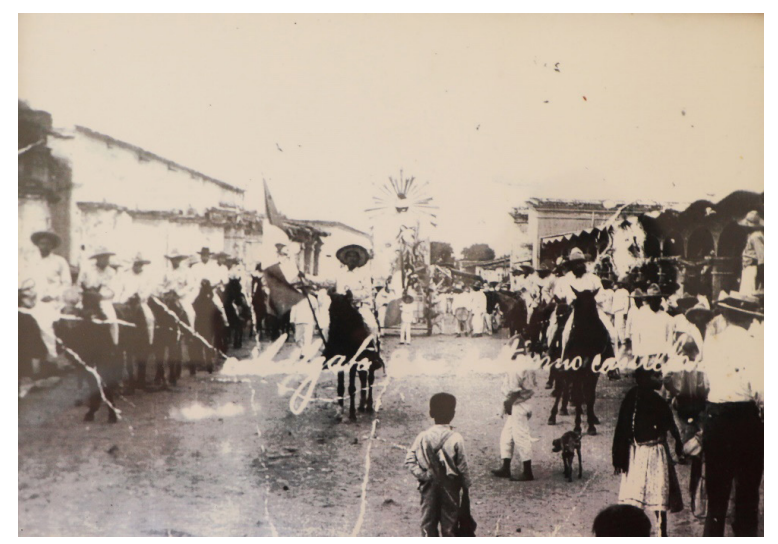

Figura 11. San Antonino Castillo Velasco, Oaxaca, México, desfile 16 de septiembre de 1915.

Fuente: Archivo municipal.

Fue en el siglo XVIII, el periodo de oro cuando Oaxaca tuvo un estatus económico alto con la producción de grana cochinilla que en mayor grado de aportación fue San Antonino de Ocotlán, hoy denominado Villa de San Antonino Castillo Velasco; de igual manera, en la producción de flores. La Villa de San Antonino Castillo Velasco, a finales del siglo XIX, contaba con un palacio municipal con carácter vernáculo y se distinguía por sus con arcadas y un frontón.

El Patrimonio Vernáculo en la Villa de San Antonino Velasco, Oaxaca, México, se ve amenazado por las fuerzas de la homogenización cultural y arquitectónica. La migración, la falta de identidad cultural, son algunas de las causas que han hecho pensar que la vivienda vernácula es sinónimo de pobreza, provocando la extinción de la arquitectura vernácula en la comunidad que tiene mucho valor histórico.
Desaparición de la Vivienda Vernácula en San Antonino Castillo Velasco, Oaxaca, México. La comercialización de nuevas tecnologías de la construcción como lo es el concreto armado, tabique rojo y tabicón, han provocado casi la extinción de las viviendas vernáculas de adobe en la Villa de San Antonino Castillo Velasco, Oaxaca, México.

En las viviendas vernáculas que aún se conservan ya sea en estado regular, o con riesgo, así como en sus muros perimetrales con bloques de adobe (Figura 12), los propietarios manifiestan que requieren apoyo técnico y financiero para conservar sus viviendas, ya que tienen arraigo con ese tipo de arquitectura como la Señora Tomasa Santiago Matías, de 85 años, que tiene su vivienda en la calle independencia \#29 en la Villa de San Antonino Castillo Velasco (Figura 13).

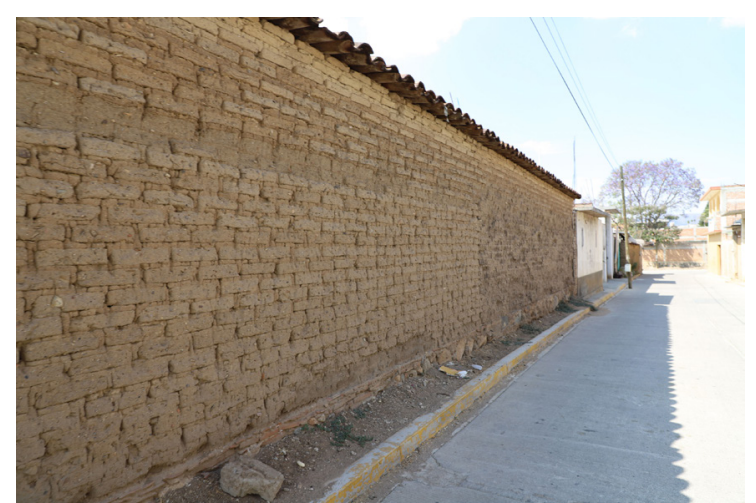

Figura 12. Muro perimetral de vivienda con características de arquitectura vernácula de adobe.

Fuente: Autores. Año 2020.

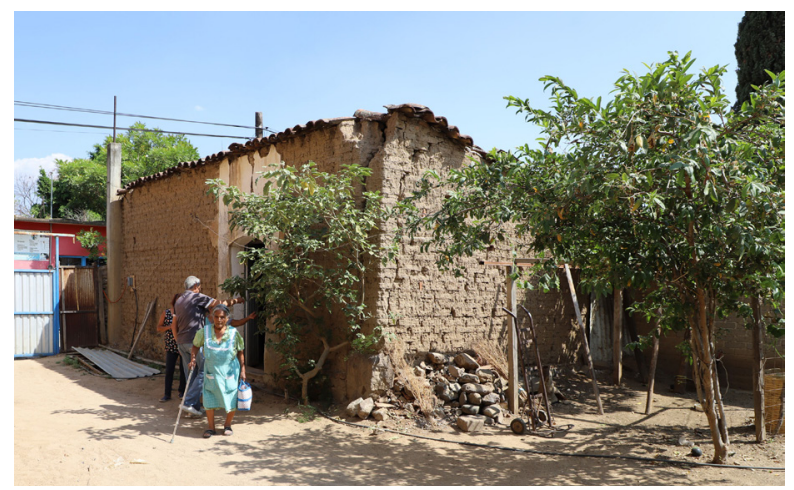

Figura 13. Vivienda con características de arquitectura vernácula con adobe en riesgo de colapso.

Fuente: Autores. Año 2020.

Se realizó un recorrido físico por todas las calles del municipio de la Villa de San Antonino Castillo Velasco, y se realizó el levantamiento fotográfico y ubicación de las viviendas vernáculas, identificando las viviendas que no son habitables por falta de 
elementos constructivos, techos, intervención en los muros, accesos, y colindancias (Figuras: 14 y 15)

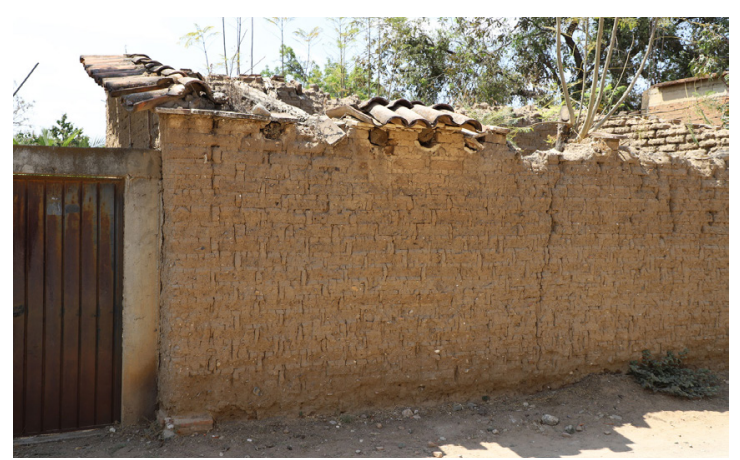

Figura 14. Vivienda con características de arquitectura vernácula con adobe, en ruinas.

Fuente: Autores. Año 2020.

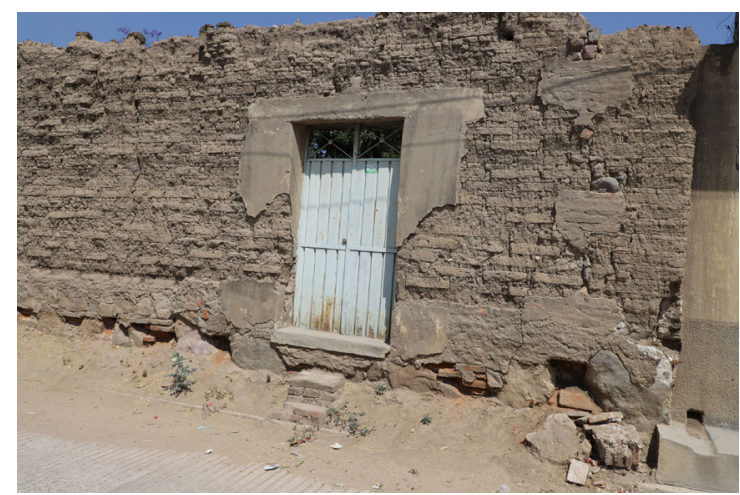

Figura 15. Vivienda con características de arquitectura vernácula con adobe, en ruinas.

Fuente: Autores. Año 2020.
También se observan viviendas que han sido dañadas en su totalidad por los sismos y por la falta de mantenimiento, y queda solo el predio con un cuarto para el propietario o propietaria.

\section{RESULTADOS}

Identificación de la Vivienda Vernácula en el Municipio de la Villa de San Antonino Castillo, Velasco, Oaxaca, México. La caracterización de la arquitectura vernácula en la Villa de San Antonino Castillo Velasco, es la manifestación con aspectos simbólicos, medio natural, recursos propios de la región, mano de obra, actividades de usos y costumbres que conforman la población que lo habita, y que deja de manifiesto su identidad, patrimonio natural y construido.

La traza urbana es de forma reticular y como hito central el Templo Católico del siglo XVII. Para realizar la investigación de campo en la identificación y registro de la vivienda vernácula, se realizó una cedula de identificación para obtener la información primaria.

Para ejecutar la investigación de campo, se obtuvo la traza urbana actualizada, misma que sirvió para la elaboración de planos divididos por Cuadrante numerándolos por Cuadrante 1, Cuadrante 2, Cuadrante 3, y Cuadrante 4, tomando como eje central el Templo Católico y el Palacio Municipal, respecto a la orientación del norte magnético (Figura 16).

Figura 16. Plano por cuadrantes. División respecto a la traza urbana, tomando de referencia el norte magnético. Elaboración propia. Autores. Año 2020. 
Como resultado de la investigación mixta, respecto a la identificación y registro de la vivienda vernácula en la Villa de San Antonino Castillo Velasco, se obtuvieron los siguientes resultados:

Conforme al censo realizado por el INEGI, el total de viviendas particulares es de 1,394 (INEGI, 2010). El INEGI, no realiza el censo de viviendas por tipología, se basa en familias y hogares.

Las viviendas vernáculas se identificaron y registraron por cuadrantes; se obtuvieron los siguientes datos: el Cuadrante 1, una (1) vivienda; Cuadrante 2 (19) viviendas; Cuadrante 3 (39) viviendas; Cuadrante 4 (156) viviendas. Cuyo resultado total son 156 viviendas con tipología vernácula con adobe. Y representa un $11.20 \%$ respecto al total de viviendas de uso particular (Tabla 1).

Tabla 1. Identificación y registro de la vivienda vernácula por Cuadrante en la Villa de San Antonino Castillo Velasco, Oaxaca, México.

\begin{tabular}{cc}
\hline Cuadrante & $\begin{array}{c}\text { Número de viviendas } \\
\text { vernáculas con adobe }\end{array}$ \\
\hline Cuadrante 1 (Noroeste) & 1 \\
Cuadrante 2 (Noreste) & 19 \\
Cuadrante 3 (Suroeste) & 39 \\
Cuadrante 4 (Sureste) & 97 \\
Total de viviendas & 156 \\
\hline
\end{tabular}

Elaboración propia. Autores. Año 2020.

De las 156 viviendas identificadas y registradas, 12 de ellas están inhabitables, no cuentan con techo, daños en muros; sin embargo, con una pronta intervención, respetando los materiales que identifican la vivienda urbana se conservan las viviendas (Figura 17).

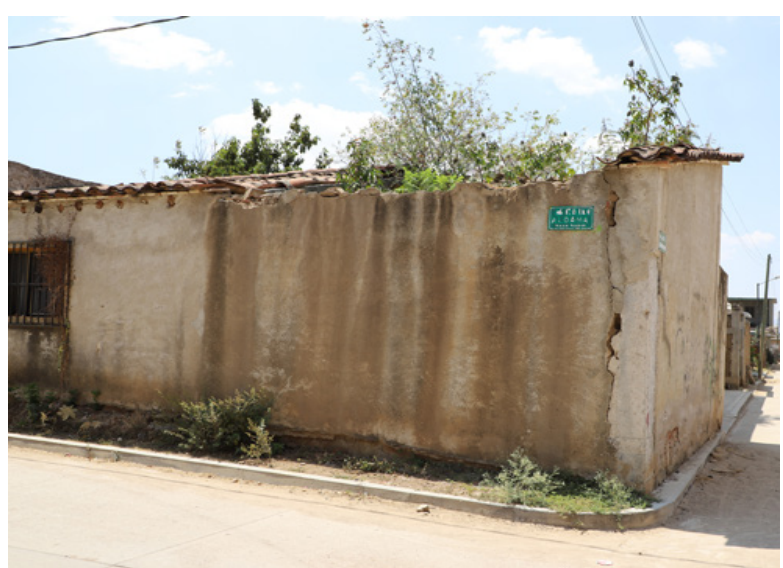

Figura 17. Vivienda Vernácula inhabitable por falta de techo. Fuente: Autores. Año. 2020.
Las viviendas vernáculas se caracterizan por su forma cuadrada o rectangular con dimensiones variables, la estancia principal se le conoce como "pieza" y tiene una forma rectangular, se distingue por el detalle de tener un altar en su interior (Figura 18).

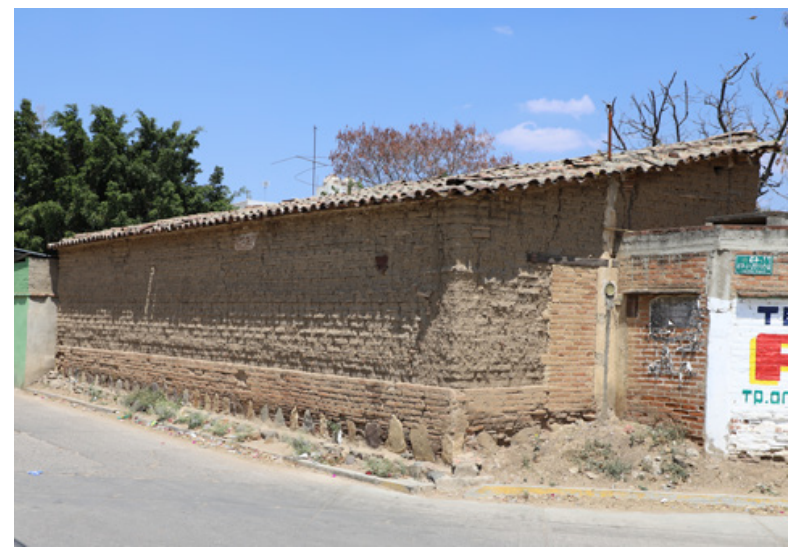

Figura 18. Vivienda Vernácula con forma rectangular, estancia principal conocida como "Pieza".

Fuente: Autores. Año. 2020.

Los diferentes sismos ocurridos durante los años 2017, 2018 han ocasionado daños en las viviendas de adobe, inclusive en las bardas perimetrales con bloques de adobe; los propietarios recurren a realizar un hibrido en las intervenciones combinando materiales industrializados con adobe, sin una debida asistencia técnica para su rehabilitación correcta. (Figura 19 y 20).

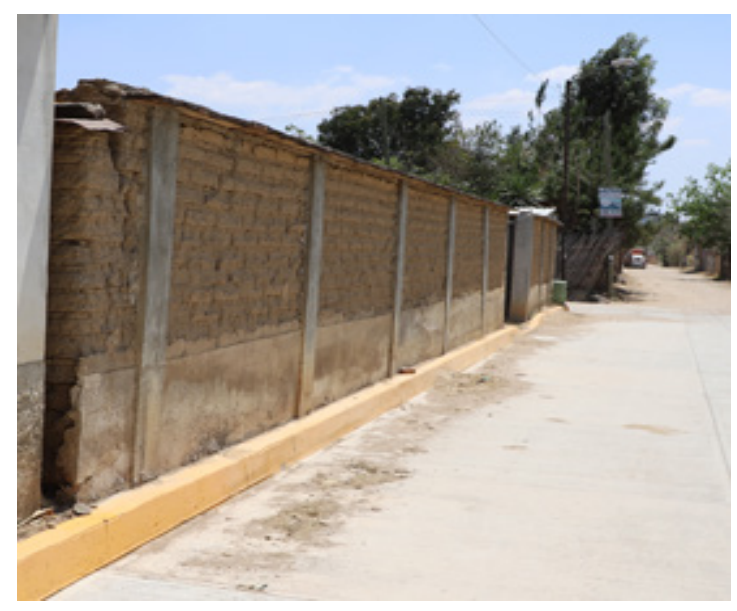

Figura 19. Muro perimetral de adobe en vivienda vernácula, se observa la inclinación del muro, intervinieron con columnas de concreto armado, falta de asistencia técnica correcta constructiva.

Fuente: Autores. 2020. 


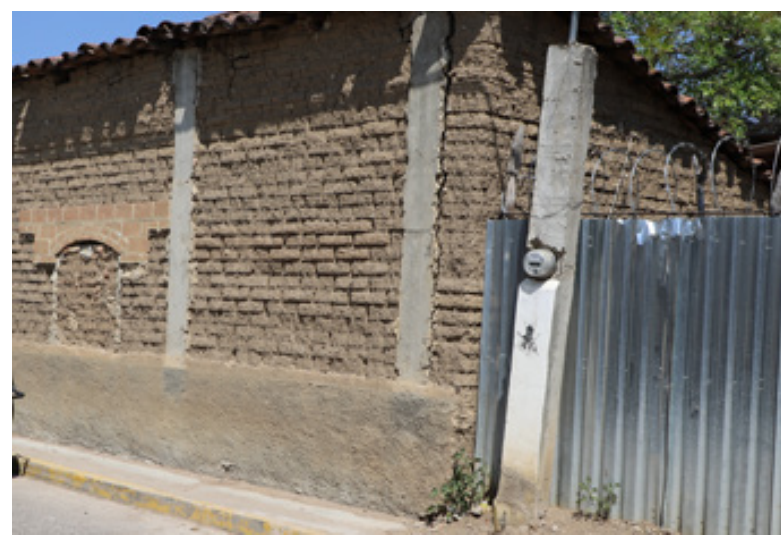

Figura 20. Vivienda vernácula con diferentes intervenciones sin asistencia técnica correcta constructiva.

Fuente: Autores. Año. 2020

La vivienda construida con materiales industrializados corresponde al 89\%; la vivienda vernácula habitable corresponde al $10 \%$; y la vivienda vernácula no habitable al $1 \%$, con respecto al total de 1,394 viviendas de uso particular (Figura 21).

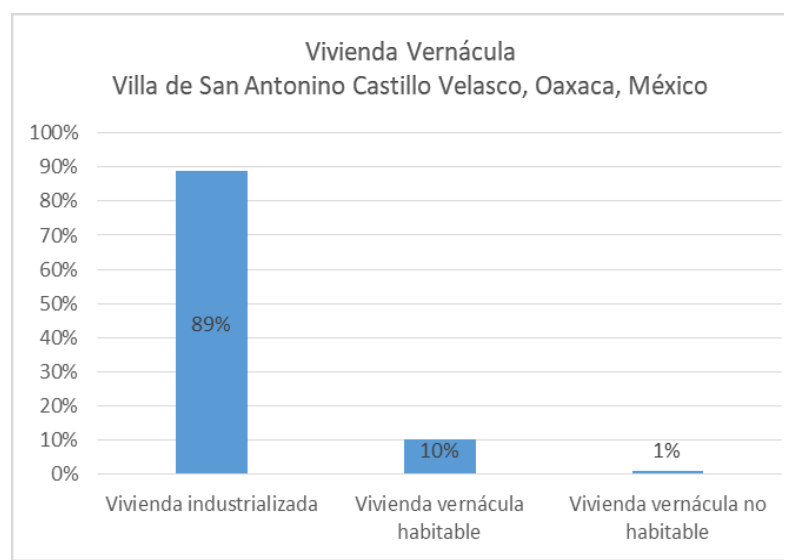

Figura 21. Identificación y registro de la vivienda vernácula de la Villa de San Antonino Castillo Velasco, Oaxaca, México.

Elaboración propia. Autores. Año 2020.

El crecimiento urbano, las actividades económicas primarias y secundarias que se desarrollan en la comunidad, y cambio de uso de suelo, influyen en los propietarios de las viviendas a construir con materiales industrializados, y sustituir la vivienda vernácula de adobe.

Se observa que la vivienda vernácula en toda la comunidad es de un solo nivel, no existen viviendas vernáculas de dos niveles o más.

\section{CONCLUSIONES, OBSERVACIONES $Y$ SUGERENCIAS}

La investigación de la vivienda vernácula en la Villa de San Antonino Castillo Velasco, llevó a la caracterización, identificación y registro de la vivienda vernácula, que tiene relación intrínseca con el medio natural y cultural, con características propias de la región; el resultado de la vivienda vernácula es que un $10 \%$ es habitable y $1 \%$ no habitable. Es urgente la intervención para su conservación mediante políticas públicas del gobierno municipal que incluyan la vivienda vernácula como parte de su historia, identidad y patrimonio cultural construido.

En las calles donde hay afectación (alineamiento y uso de suelo) por la traza urbana existen viviendas de construcción con muros de adobe perimetrales en mal estado, y representa un riesgo para los transeúntes; se recomienda un programa de protección civil para reportar al Gobierno municipal los muros con adobe que representen daños severos y, en su caso, realizar la intervención técnica correcta, respetando la tipología y características de los materiales de la vivienda vernácula.

El crecimiento urbano representa una transición productiva, pasando por la actividad agrícola a los sectores secundario y terciario, en el Plan de Desarrollo Municipal, de considerar una proyección urbana que se integre a las necesidades de toda la comunidad y la puesta en valor de la vivienda vernácula.

Para la intervención de la vivienda vernácula es indispensable contar con el apoyo técnico especializado para su correcta ejecución, respetando los materiales de la región.

Hay interés por parte de los propietarios de las viviendas vernáculas para conservarlas ya que en ella existen recuerdos de sus antepasados y las generaciones presentes valoran lo intangible. Se recomienda la gestión ante el gobierno municipal, estatal, federal, organizaciones civiles, organizaciones no gubernamentales para el apoyo económico y realizar la conservación correcta de la vivienda.

Se sugiere un reglamento de construcción para la vivienda vernácula que involucre las técnicas y métodos científicos para su respectiva conservación. 


\section{REFERENCIAS}

Archivo Municipal del Municipio de la Villa de San Antonino Castillo Velasco. Oaxaca, México. Año. 2020.

Cedula de Información Básica para Centros Estratégicos Comunitarios (CIBCEC, 2003). Secretaría de Desarrollo Social. México. http://www.microrregiones.gob.mx/cibcec06/indice. aspx?tipo $=$ clave $\&$ campo $=$ micro $\&$ valor $=2020$

González, J. (1996) La casa de tradición azteca en la ciudad de México. Siglos XVI y XVII. Tesis Maestría. UNAM.

Internacional Council on Monuments and Sites. (ICOMOS, 1999). Carta del Patrimonio Vernáculo Construido. México, 1999.

Instituto Nacional de Estadística, Geografía e Informática. (INEGI, 2015). Encuesta Intercensal. https:// www.inegi.org. $\mathrm{mx} / \mathrm{rnm} /$ index.php/catalog/214\#: : text=El\%20Instituto\%20Nacional\%20de\%20 Estad\%C3\%ADsticas,realiz\%C3\%B3\%20la\%20Encuesta\%20Intercensal\%202015.

Instituto Nacional de Estadística, Geografía e Informática. (INEGI, 2010). Censo de Población y Vivienda. https:// www.inegi.org.mx/programas/ccpv/2010/\#: : text=El\%20prop\%C3\%B3sito\%20fundamental\%20 del\%20Censo,y\%20captar\%20datos\%20sobre\%20sus

León, M. (1997). La filosofía náhuatl. UNAM. México.

López, F. (1989). Arquitectura Vernácula en México. Trillas. México.

United Nations Educational Scientific and Cultural Organization. (UNESCO, 2003). Convención para la salvaguardia del patrimonio cultural inmaterial. Paris. 2003. 